\title{
Smog - Poland's pressing problem. Anti-smog technologies
}

\author{
Jan Kiciński ${ }^{1, *}$ \\ ${ }^{1}$ Polish Academy of Sciences, Institute of Fluid Flow Machinery, Generała Józefa Fiszera 14, \\ 80-231 Gdańsk, Poland
}

\begin{abstract}
The article also presents the situation of the Polish power engineering against the background of global trends, as well as proposals for solving the smog problem using anti-smog technologies developed at the Institute of Fluid-Flow Machinery of the Polish Academy of Sciences in Gdańsk (IMP PAN) and by launching a pilot project that will cover 1,000 households equipped with these technologies. The author and his closest coworkers recommend equipping boilers, including both older and newer ones, with low-power electrostatic precipitators. In this way, one can burn lowquality fuels while keeping the emission of airborne dust at a low level. It is a quick and not pricey solution to the smog problem.
\end{abstract}

\section{Introduction}

Scale of the problem. There are about 13.4 million households in Poland. Most of them $(55.5 \%)$ are located in multi-family houses, and $44.5 \%$ in single-family houses. Currently, approximately 5-6 million households utilise coal and biomass for heating buildings and utility water. The vast majority of them use older generation boilers, which have lowefficiency ratings and high emission levels of pollutants. The oldest devices include solid fuel stoves (whose average age exceeds 24 years) and boilers (the average age of which is 10 years). On the other hand, the share of boilers and solid fuel stoves as sources of pollution to the atmosphere in Poland is estimated at over $90 \%$.

Smog originates from energy poverty, we burn everything that has a calorific value!

So, how to solve the problem of smog? Do we have anti-smog technologies suitable for rapid implementation in our country?

An example of anti-smog technologies with a high degree level of technological readiness are the installations developed at the Institute of Fluid-Flow Machinery of the Polish Academy of Sciences in Gdańsk. At this point, it is worth mentioning the results of the works of research teams managed by Prof. D. Kardaś (low-emission boilers [3,4]), Prof. M. Dors, Dr. J. Podliński, Prof. A. Jaworek (electrostatic precipitators [5-9]), Prof. J. Kiciński and Dr. G. Żywica (micro power plants [1,2]), Dr. M. Lackowski (energy storage) as well as Prof. A. Cenian and Prof. P. Lampart (gasifiers, biogas power plants and ORC systems [10]).

The work of these teams led to the development of technologies which Poland so desperately needs.

* Corresponding author: jan.kicinski@imp.gda.pl 


\section{Anti-smog technologies elaborated in IMP PAN}

There were proposed four stages of the implementation of these innovative technologies:

- equipping older generation domestic boilers with low-power electrostatic precipitators (IMP PAN patent No. P. 422507). Fast and relatively cheap implementation;

- development of technologically advanced coal-fired boilers with very low levels of dust emissions, equipped with electrostatic precipitators;

- introduction into the market of domestic micro power plants that enable the production of heat and electricity and can replace central heating boilers;

- introduction into the market of a series of micro-cogeneration power plants that can meet the energy needs of small companies, public buildings and multi-family houses.

\subsection{Low-power electrostatic precipitator for use in older generation boilers operating in domestic installations (IMP PAN patent No. P. 422507)}
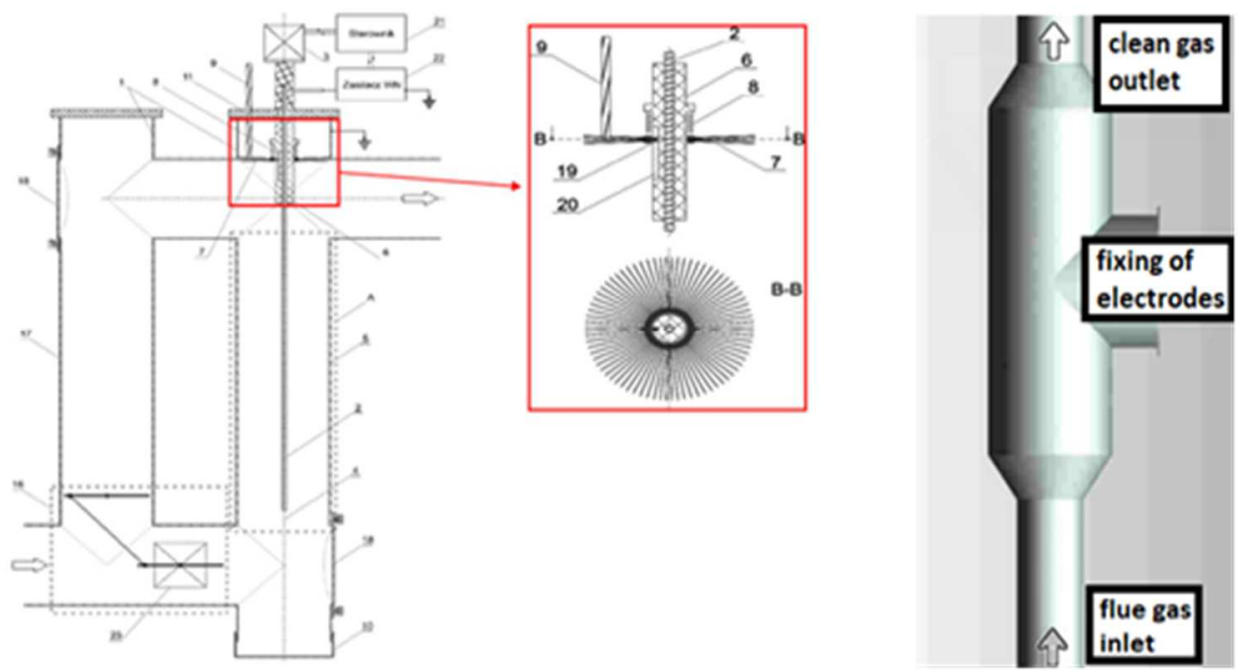

Fig. 1. Low-power electrostatic precipitator and its schematic diagram (for use in domestic boilers with thermal power capacities ranging from $20 \mathrm{~kW}$ to $30 \mathrm{~kW}$ ) [19-25]

Device characteristics:

- quick implementation is possible, high degree of technological readiness (the device already passed laboratory tests and operational tests of the pilot installation),

- dust removal efficiency reached $90 \%$,

- the price of one electrostatic precipitator would not be higher than PLN 2,000 (assuming the mass production).

Remark: Even though it is fast and cheap, it is not the ultimate solution to the problem.

\subsection{Ultra-low emission coal boiler (highly efficient device plus an electrostatic precipitator)}

The boiler enables combustion of various types of low-quality fuels (e.g. coal-mine waste that is much cheaper than eco-pea coal), and thanks to the use of the electrostatic precipitator the concentration of airborne dust can be kept at a low level.

This is a very attractive solution. 
Characteristics of the installation:

- the electrostatic precipitator for a lower class boiler is a temporary solution. An ultralow emission coal boiler equipped with an electrostatic precipitator is a more forwardthinking solution;

- the total manufacturing cost of an ultra-low emission coal boiler is PLN 10,600. Having analysed the market of central heating boilers, it can be said that the selling prices of coal boilers with a capacity of approx. $25 \mathrm{~kW}$ (class V according to the PN EN 303 5:2012 standard) range from PLN 11,600 (Draco Versa Tekla) to PLN 12,600 (EGRO PLUS Witkowski);

- the cost of an ultra-low emission boiler with a capacity of $20 \mathrm{~kW}$ will be paid back after 2.5 years, and the profit from its use will exceed PLN 40,000 within 10 years;

- $\quad$ high degree of technological readiness (after laboratory tests).

An ultra-low emission domestic boiler will be an original solution based on a highly efficient combustion process at elevated temperatures, with a two-stage heating and will be equipped with an electrostatic separator of solid particles. In addition to increased energy efficiency, this solution will enable the use of low-quality solid fuels, i.e. coal dust containing a higher percentage of minerals, which will significantly reduce exploitation expenses. A product of this kind is not available either on the Polish or European market.
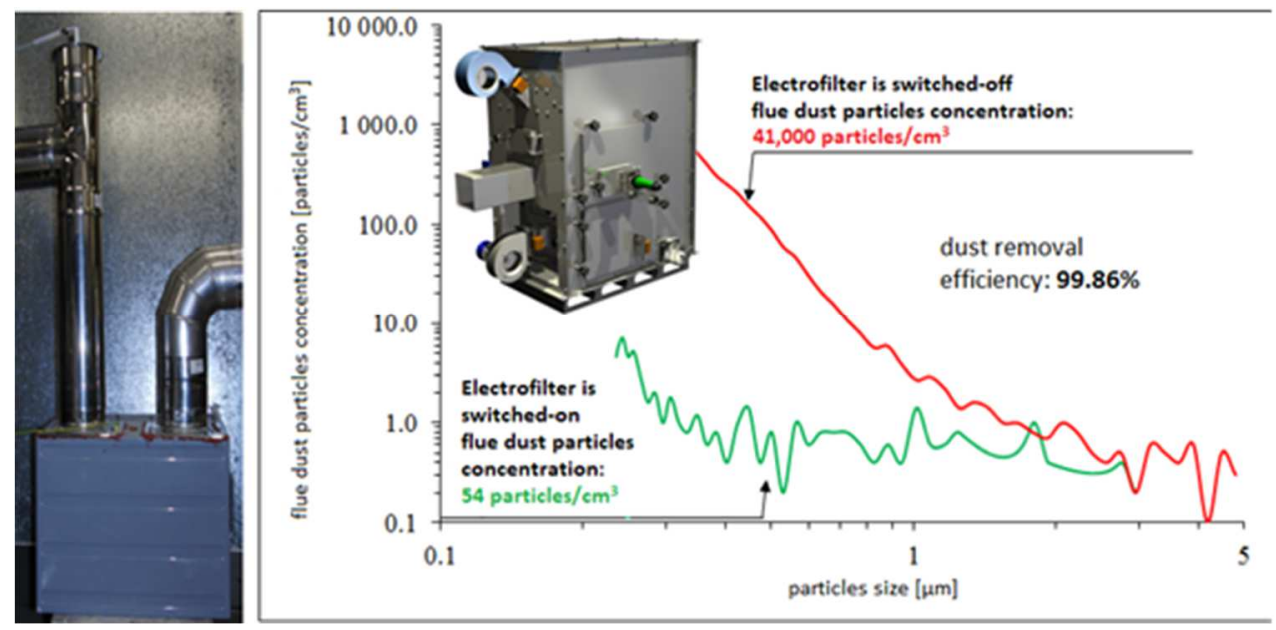

Fig. 2. Electrostatic precipitator behind the flue and the graph that shows the dust emission reduction. The dust removal efficiency is $99.86 \%$ [19-25].

\subsection{Domestic cogeneration power plant (low-emission boiler, microturbine, electrostatic precipitator)}

Characteristics of the installation:

- it is the most forward-thinking solution that allows producing heat and electricity in households while, at the same time, providing low emission levels of pollutants.

- The installation passed laboratory tests, a pilot installation is currently under construction.

- A coal-fired or wood-fired domestic micro power plant will be profitable mainly due to the synergy between the production of heat and electricity (cogeneration). Achieving profits from the production and sale of electricity can lead to a situation in which the technology demonstrated herein will become a technology of the future from the point of view of civic power engineering. 
- It is estimated that a micro power plant with a thermal power capacity of $30 \mathrm{~kW}$ and an electric power capacity of $4.5 \mathrm{~kW}$ can give an income of PLN 1,000 a month.
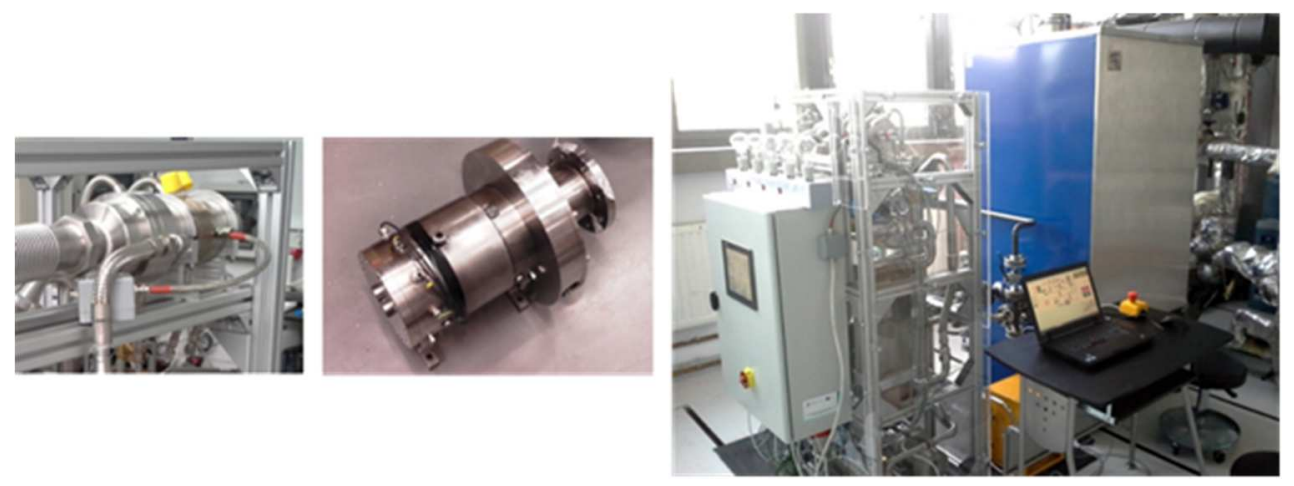

Fig. 3. Micro power plant with a thermal power capacity of $25 \mathrm{~kW}$ and an electric power capacity of $2.5 \mathrm{~kW}$. On the left-hand side: microturbines operating in the ORC system [18, $19-25]$.

\subsection{Scaling. Series of power plants with higher power capacities}

The technologies listed in sections I, II and III relate to installations for use in small households, which mainly emit particulate pollutants. However, there are still municipal boiler rooms, boiler rooms for public utility buildings, etc., and all of them have a significant share in air pollution. For this market segment, it is worth developing anti-smog technologies for devices with higher thermal (several hundred kilowatts) and electric $(20-30 \mathrm{~kW})$ power capacity.

Mostly owners of large farms will be buyers of micro power plants with electric power capacities exceeding 20kW. There are over 30,000 large farms in Poland (with an area of land above $50 \mathrm{ha}$ ) and their owners are potential recipients of micro power plants. Another very important group of buyers of micro power plants will be municipal enterprises from small towns, which use hard coal as a basic source of thermal energy. In Poland there are 2,478 municipalities (of which 1,563 are rural municipalities). Assuming that each rural municipality has a school and a public building (e.g. a municipal office) that need heat and electricity, this gives a total of more than 3,000 potential users of the device.

In Poland, there are at least 50,000 potential buyers of solid fuel fuelled gas turbine systems with an electric power capacity of approximately $30 \mathrm{~kW}$. That number covers large farms, small and medium-sized production and service enterprises from the agricultural and forestry sectors as well as municipal entities managed by local authorities.

\section{Fight for clean air}

The most advanced and most profitable method of fighting for clean air is to completely transform the existing farm heating system in Poland into the distributed power engineering based on small installation capable of generating electricity and heat. These installations would use cheap coal and locally available biomass as fuel. A transformation of domestic boilers and local heating-generating plants into small heat and power plants will additionally result in a drastic reduction of dust emissions, which will take place due to the need to maintain high operational efficiency of all components of micro and mini power plants.

Poland has a chance to become a vast repository of knowledge about air pollution, its formation, impact on people and the environment, but also a centre for technologies for the ecologically-friendly use of solid fuels as well as prevention and elimination of smog. The 
goal could be to make Poland the global leader in the field of eco-friendly utilisation of solid fuels for heating households and for the cogeneration of heat and electricity.

Domestic cogeneration power plants can be perceived as the last stage of the fight for clean air. In the first stage, it is worth implementing low-power electrostatic precipitators in both older and newer generation boilers.

The use of low-power electrostatic precipitators for both old and new generation boilers can help a lot in this fight. According to the estimates, one electrostatic precipitator will cost no more than PLN 2,500 (assuming the mass production), which seems to be a reasonable price. The eco-pea coal, the calorific value of which is at least $24 \mathrm{MJ} / \mathrm{kg}$, is currently sold for PLN 775 per tonne whilst the small coal from the Wujek mine with the same calorific value is sold for PLN 509 per tonne. Also in other places in the country, there are big differences in the price of these two types of coal. For example, in the Carbon company from the city of Kielce, the cheapest coal of the eco-pea type is sold for PLN 787 per tonne and the small coal is sold for PLN 537 per tonne. In other companies, the difference between the price of ecopea coal and small coal is usually around PLN 250 per tonne. The old generation boiler with an electrostatic precipitator can be fuelled with cheaper coal and the emission of pollutants will be the same as in modern $\mathrm{V}$ class boilers!

\section{National Centre for clean air}

Considering the above facts, it seems justified and urgent to establish instruments for financing innovative anti-smog technologies and, in particular, state funds for launching a pilot series of electrostatic precipitators or a set of boilers with electrostatic precipitators, e.g. in 1,000 households. Such activities seem to be a very good idea due to the reluctance of homeowners as well as local authorities to incur additional costs in the name of environmental protection.

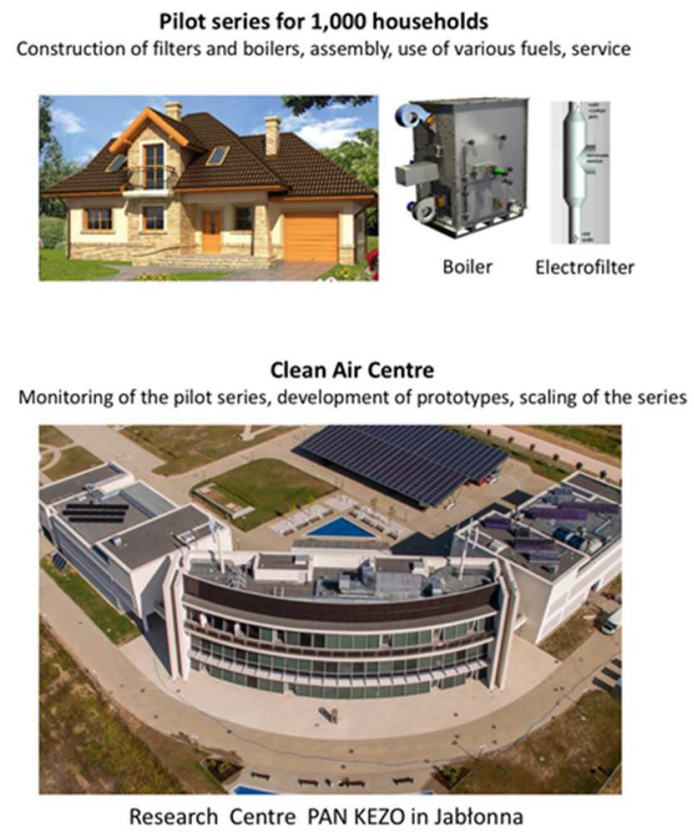

Fig. 4. Postulate for launching a pilot series of installations equipped with boilers and electrostatic precipitators (e.g. for 1,000 households), and the proposal of its monitoring and developing new prototypes at the Research Centre PAN in Jabłonna 
This is a task for the state. And it is feasible because the total estimated costs of such a pilot series (manufacturing and assembling electrostatic precipitators and boilers, testing of various fuels and boilers and their service) should not exceed PLN 10 million. The author of this article finds this amount acceptable, considering the importance and scale of the problem.

Activities related to the development of these technologies, including scaling, monitoring and training, could take place at the Research Centre PAN in Jabłonna. It would become a national centre for clean air technologies - Clean Air Centre (Fig. 4). This choice is not accidental. It is the most modern centre in the country and third in Europe in the field of energy conversion and renewable sources of energy (with well-equipped laboratories).

The KEZO centre is considered to be the Centre of Excellence in the field of small-scale clean energy technologies, mainly due to:

- membership in international organisations:

- $\quad$ EERA - European Energy Research Alliance (175 research entities and universities)

- $\quad$ ESEIA - European Sustainable Energy Innovation Alliance.

- coordination of the Horizon 2020 project entitled "SuPREME: Twinning for a Sustainable, Proactive Research partnership in distributed Energy systems planning, Modelling and management".

\section{Conclusion}

Smog originates from energy poverty, we burn everything that has a calorific value. New technologies: a low-power electrostatic precipitator installed in the boiler that enables combustion of various types of low-quality fuels is an attractive offer for households.

Launching a pilot series of installations equipped with boilers and electrostatic precipitators (e.g. for 1,000 households), which would be financed by the state is a proposal that can overcome existing difficulties in implementing new anti-smog technologies.

I hereby would like to thank my closest co-workers from the Institute of Fluid-Flow Machinery of the Polish Academy of Sciences in Gdańsk, and especially Prof. D. Kardaś, Prof. M. Dors, Prof. A. Jaworek, Dr. J. Podliński, Dr. M. Lackowski, Dr. G. Żywica, Prof. A. Cenian, Prof. P. Lampart and MSc S. Bykuć.

I also direct my words of gratitude to Msc J. Sawicki for the results achieved in the field of Industry 4.0 and the institute's position achieved due to it. Finally, I would like to give my special thanks to Mrs $\mathrm{U}$. Kokosińska as well as to Mr K. Woźniak and Mr W. Czapla for the fruitful cooperation with Human World company.

\section{References}

1. Kiciński J., Do we have a chance for small-scale energy generation? The examples of technologies and devices for distributed energy systems in micro \& small scale in Poland, Bulletin of the Polish Academy of Sciences, 61, 4, (2013)

2. Kiciński J., Żywica G., Steam Microturbines in Distributed Cogeneration, Springer, ISBN 978-3-319-12017-1, (2014)

3. [3] D. Kardaś, G. Żywica, P. Klonowicz, Small domestic power engineering, "Nowa Energia" 2, (2017)

4. Kardaś D., Turzyński T., Ronewicz K., Combustion and heat transfer processes in biomass-fuelled boilers, IMP PAN Publishers, Gdańsk, Poland, (2015)

5. Podliński J., Niewulis A., Shapoval V., Mizeraczyk J., Electrohydrodynamic secondary flow and particle collection efficiency in a one-sided spike-plate type electrostatic precipitator, IEEE Transactions on Dielectrics and Electrical Insulation, 18, 5 (2011) 
6. Podliński J., Niewulis A., Mizeraczyk J., Atten P., ESP performance for various dust densities, Journal of Electrostatics, 66, 5-6, pp. 246-253, May (2008)

7. Podliński J., Niewulis A., Mizeraczyk J., Electrohydrodynamic flow and particle collection efficiency of a spike-plate type electrostatic precipitator, Journal of Electrostatics, 67, 2-3, pp. 99-104, May (2009)

8. Jaworek A., Marchewicz A., Sobczyk A. T., Krupa A., Czech T., Two-stage electrostatic precipitator with co- and counter-flow particle prechargers, Journal of Electrostatics, 87, pp. 180-190, June (2017)

9. Jaworek A., Marchewicz A., Sobczyk A. T., Krupa A., Czech T., Two-stage electrostatic precipitator with dual-corona particle precharger for PM2.5 particles removal, Journal of Cleaner Production, 164, pp. 1645-1664 (2017)

10. Lackowski M., Karwacki J., Przybyliński T., Heda Ł., Kluska J., Cenian A., Lampart P., Measurement of characteristics of the cogeneration installation equipped with a biomass gasifier in Szepietowo (2016) 